The Editor-in-Chief's recommendation of this issue's article to readers;

\title{
COMPARISON OF MINERAL TRIOXIDE AGGREGATE, ENDOSEQUENCE ROOT REPAIR MATERIAL, AND BIODENTINE USED FOR REPAIRING ROOT PERFORATIONS: A SYSTEMATIC REVIEW
}

I am pleased to inform you that I have chosen this article by Alghamdi and Alhajdali ${ }^{1}$ as Editor-inChief's Choice for the last issue of 2019.

Calcium silicate-based cements are widely used in dental procedures and pediatric dentistry. There are several advantages of these cements which lead to increase the clinical outcome of dental treatment.
This systematic review confirmed that there none of the materials discussed had all the major properties higher than the others, this way it is required the enforcement of further studies aimed at selecting the best characteristics of the material suggested in the root perforation treatment.

Happy readings in the last issue of 2019 !

Burak Buldur

Co-Editor-in-Chief

\section{REFERENCE:}

1. Alghamdi F, Aljahdali E. Comparison of Mineral Trioxide Aggregate, Endosequence Root Repair Material, And Biodentine Used for Repairing Root Perforations: A Systematic Review. Cumhuriyet Dent J 2019;22:4:469-476. 